\title{
Chemoprophylaxis for malaria - in pregnancy by public and private health providers in Lagos
}

\author{
*Akodu BA. ${ }^{1}$, Amaechi BO. ${ }^{1}$, Inem V.
}

\begin{abstract}
Objectives: Malaria in pregnancy is a major public health problems contributing significantly to high morbidity and mortality. Intermittent preventive treatment of malaria during pregnancy (IPTp) is a key intervention in the national strategy for malaria control, Sulphadoxine-Pyrimethamine, the current drug of choice, is recommended to be administered in the second and third trimesters of pregnancy during antenatal care (ANC) visits. Aim was therefore, to determine and compare the provision of chemoprevention using intermittent preventive treatment (IPTp) in public and private secondary hospitals in Lagos State.
\end{abstract}

Method: This is a comparative, cross sectional study that assessed the factors influencing health care providers - provision of chemoprohylaxis - in public and private secondary health facilities in Lagos State. Data was collected using a pretested questionnaires administered to 302 healthcare providers selected through multistage sampling. Data generated was analysed with Epi-Info 2012 version.

Results: The private providers had a better practice and provision of chemotherapy. Only $69.0 \%$ of public providers and $74.8 \%$ of private providers prescribed IPT using sulphadoxine-pyrimethamine. The private providers were more aware of the timing (recommended time to give IPTp) of IPTp.

Conclusion: Both public and private health care providers have not fully embraced the evidence based World Health Organization recommendation of administration of least two doses of sulphadoxinepyrimethamine for malaria in pregnancy.

Keywords: Chemoprophylaxis, Malaria, Pregnancy.

*Correspondence Author: Akodu Babatunde A. : Email: babakodu@gmail.com

${ }^{1}$ Department of Family Medicine, Lagos University Teaching Hospital, Idi-Araba, Lagos State, Nigeria.

${ }^{2}$ Department of Community Health and Primary Care, College of Medicine University of Lagos, Nigeria.

Research Journal of Health Sciences subscribed to terms and conditions of Open Access publication. Articles are distributed under the terms of Creative Commons Licence (CC BY-NC-ND 4.0). (http://creativecommons.org/licences/by-nc-nd/4.0).

http://dx.doi.org/10.4314/rejhs.v5i2.6 


\title{
Chimioprophylaxie contre le paludisme - pendant la grossesse par des prestataires de soins publics et privés à Lagos
}

\begin{abstract}
*Akodu BA. ${ }^{1}$, Amaechi BO. ${ }^{1}$, Inem V. $^{2}$
Resume

Objectifs: Le paludisme pendant la grossesse est un problème majeur de santé publique qui contribue de manière significative à la morbidité et à la mortalité élevées. Le traitement préventif intermittent du paludisme pendant la grossesse (IPTp) est une intervention clé dans la stratégie nationale de lutte contre le paludisme, la sulphadoxine-pyriméthamine, le médicament actuel de choix, est recommandée pour être administrée au deuxième et troisième trimestre de la grossesse pendant les soins prénatals (ANC) Visites. L'objectif était donc de déterminer et de comparer la fourniture de chimioprévention en utilisant un traitement préventif intermittent (IPTp) dans les hôpitaux secondaires publics et privés dans l'État de Lagos.
\end{abstract}

Méthode: étude comparative et transversale qui a évalué les facteurs qui influencent les fournisseurs de soins de santé - la fourniture de chimioprophylaxie - dans les établissements de santé secondaire publics et privés dans l'État de Lagos. Les données ont été recueillies à l'aide d'un questionnaire prétesté administré à 302 fournisseurs de soins de santé sélectionnés par échantillonnage multi-étapes. Les données générées ont été analysées avec la version Epi-Info 2012.

Résultats: les prestataires privés ont une meilleure pratique et une meilleure chimiothérapie. Seulement $69,0 \%$ des prestataires publics et $74,8 \%$ des prestataires privés ont prescrit l'IPT en utilisant de la sulfatexine-pyriméthamine. Les fournisseurs privés étaient plus conscients du moment (temps recommandé pour donner IPTp) de IPTp.

Conclusion: Les fournisseurs de soins de santé publics et privés n'ont pas pleinement accepté la recommandation de l'Organisation mondiale de la santé fondée sur les preuves d'administrer au moins deux doses de sulfatexine-pyriméthamine pour le paludisme pendant la grossesse.

Mots-clés: Chimioprophylaxie, Malaria, Grossesse.

*CorrespondanceAuteur: Akodu BabatundeA. : Email: babakodu@gmail.com

${ }^{1}$ Department of Family Medicine, Lagos University Teaching Hospital, Idi-Araba, Lagos State, Nigeria.

${ }^{2}$ Department of Community Health and Primary Care, College of Medicine University of Lagos, Nigeria. 


\section{INTRODUCTION}

The first malaria preventive strategies were implemented in the 1950s. They consisted of weekly or bi-monthly chemoprophylaxis with chloroquine (CQ) in West African Countries and dapsone -pyrimethamine or Sulphadoxine pyrimethamine (SP) in East African Countries (1). In 1998, it was proposed, then finally implemented in 2004, that chemoprophylaxis using daily or weekly drugs should no longer be recommended, but replaced by intermittent preventive treatment for all pregnant women living in areas of stable malaria transmission $(1,2)$.

The control of malaria infection in pregnancy requires multidimensional approach. World Health Organization recommended control of malaria in pregnancy in areas of stable transmission through effective case management of malaria, -the use of intermittent preventive treatment of malaria in pregnancy with at least two doses of sulphadoxine-pyrimethamine and the use of insecticide treated nets (ITNS) $(3,4)$

Nigeria adopted intermittent preventive treatment of malaria in pregnancy (IPTp) as a strategy in 2005 to replace weekly prophylaxis (5). Unlike the prophylactic anti-malarial drugs that are given at less than therapeutic dose at regular interval that could encourage parasite resistance, the IPTp using sulphadoxine pyrimethamine employs administration of full curative dose regimen at pre-defined intervals during pregnancy.

The drug is given irrespective of peripheral blood malaria parasite states and should be given to all pregnant women after 16 weeks of pregnancy (6). While two doses were found more efficacious than single dose; some, studies have found that three or more doses of SP are more efficacious than two doses in HIVpositive mothers (7), but no benefit was found in HIV-negative women (1). The treatment doses are given at least one month apart in the second and third trimesters (6). Administered at least twice during pregnancy regardless whether or not the woman has malaria and best be linked to routine scheduled ante-natal visits after quickening $(1,6)$. The effectiveness of sulphadoxine - pyrimethamine in improving birth weight reducing prevalence of preterm deliveries and maternal anaemia was reported in Nigeria $(7,8)$.

The coverage of IPTp is low in Nigeria (6), only $18 \%$ pregnant women received an antimalarial drug for the prevention of malaria during pregnancy, $11 \%$ received at least one dose of SP and 7\% received two or more doses (6). Therefore, it is necessary to assess the level of provision of IPTp and understand the underlying reasons behind the level of provision in both private and public health providers,

Efforts have been made to alleviate the problem of malaria in pregnancy, this include the WHO recommendation of prompt and effective management of malaria in pregnancy, chemoprophylaxis, the use of long lasting insecticide nets and indoor residential spraying (IRS) and the use of IPTp $(6,9)$.

Many researchers have reported high prevalence rates of malaria in pregnancy in different parts of Nigeria, ranging $19.7 \%$ to $72.0 \%$ (10). Also the procurement of antimalarials made through public health services increased sharply but access to treatment especially ACT in particular was inadequate in all countries surveyed in 2006 (11). Malaria is responsible for $30 \%$ childhood mortality and $11 \%$ of maternal mortality and more than $60 \%$ out-patient visits in Nigeria are due to malaria and it also accounts for $30 \%$ of all hospital admission with nearly 110 million cases and 300,000 deaths per year $(5,6)$. From the above it is evident that access and consumption of effective intervention is still low and malaria in pregnancy continue to constitute a huge burden.

Hence, this study was conducted to determine the provision and use of drugs forprevention of malaria in pregnancy in public and private hospitals in Lagos. This can highlight public and private health institutions efforts in prevention and control of malaria in pregnancy, findings of which may influence policy change.

Aim was to determine and compare the provision of chemoprevention using intermittent preventive treatment (IPTp) in public and private secondary hospitals in Lagos State.

\section{MATERIALS AND METHODS}

This was a comparative cross-sectional study. Study population consisted of health care providers involved in ante-natal services in public and private secondary health facilities in Lagos State. Data was collected using a pretested questionnaires administered to 302 healthcare providers selected through multistage sampling at the selected healthcare facilities in the month of June to July, 2013. The questionnaire contained questions on the socio-demographic characteristics of the respondents, facility type and provision of chemoprevention. Data entry 
and analysis was done using Epi-info. 7 0.9.7 Version. A univariate was carried out to generate frequencies and proportions and bivariate analysis to test for associations between the independent and the outcome variables.

The data obtained was presented as tables and figures. Chi-square $\left(\mathrm{X}^{2}\right)$ test was used to test for association between the independent and dependent variables at probability value $=<0.05$.

Ethical approval was obtained from Lagos University Teaching Hospital, Health Research and Ethics Committee (LUTH HREC). Approval for the study was also sought from the authorities of all selected facilities. Each participant signed a written informed consent form.

\section{RESULTS}

A total of 302 questionnaires were administered, of these 290 were retrieved and sufficiently completed to permit detailed analysis giving a response rate of $96 \%$

Table 1 showed that the majority $(84.2 \%)$ of the providers in the public facility were between the ages of 25-44years of age while a relatively lesser proportion (64.71\%) was within the same age group in the private facility.

No statistically significant difference was found between the age of the providers in the public and private facility. The mean ages of providers in the public and private facilities were $35.08 \pm 7.57 \mathrm{SD}$ years and $33.97 \pm 10.82 \mathrm{SD}$ respectively.

Majority $(71.9 \%)$ of the providers in public facility were married, while relatively lesser proportions (60.55) in the private facility were married. There was however a statistically significant difference in their marital status. The providers were predominantly Christians in both facilities $(77.8 \%$ and $96.6 \%)$ with statistically significant difference found in their religion. Yorubas formed the highest respondents $(70.8 \%)$ in the public facility as against $(36.1 \%)$ it formed in private facility. There was statistically significant difference in their ethnicity.

Providers in the public facility were predominantly $(64.9 \%)$ doctors while a lesser proportion $(39.5 \%)$ in the private facility were doctors and there was statistically significance difference in their professional category.

Table 2 showed that Less than one-third $(31.6 \%)$ in public and $(31.1 \%)$ in private still used Chloroquine, Daraprin and Paludrine in provision of chemoprevention of malaria in pregnancy without IPTp, there is no statistically significant difference in their choice. In the reason for their choice $(22.8 \%)$ of public and $(24.4 \%)$ of private providers believe it is effective.

No statistically significant difference in their belief. In the public facilities $(72.5 \%)$ of the providers have provided less than 50 pregnant women with chemoprophylaxis in the past one month and $(82.5 \%)$ of the private providers also provided less than 50 pregnant women with chemoprophylaxis in the past one year. This is followed by $(17.0 \%)$ in the public and (15.1\%) in private that have seen between 51 to 100 pregnant women, while $(10.5 \%)$ in public and $(2.5 \%)$ in private that have seen above 100 pregnant women in the past one month. The mean number of pregnant women seen in the past one month was $59.03+75.60$ and $40.88+40.43$ by public and private providers respectively. There was statistically significant difference in the mean number of pregnant women seen by both providers $(\mathrm{p}<0.05)$.

Table $2 \mathrm{~b}$ showed that majority $(69.0 \%)$ of public providers and $(74.8 \%)$ of private p r o viders $\quad$ p r e s ribe sulphadoxine/pyrimethamine for chemoprophylaxis of MIP. This is followed by ACT which formed $(28.7 \%)$ in public and (29.4\%) in private facilities while Chloroquine, Quinine and Artemisinin monotherapy formed $(19.3 \%, 12.9 \%$ and $11.7 \%)$ respectively in public and $(17.6 \%, 1.7 \%$ and $10.1 \%)$ respectively in private. There was no statistically significant difference in their choice of drugs.

Table 3 showed that majority (93.6\%) of public and $(99.2 \%)$ of private confirmed that they used IPTp as preventive strategy. There was statistically significant difference in their usage $(p<0.05)$. For those not using it, among public providers, $1.8 \%, 0.6 \%$ and $0.6 \%$ respectively said that hospital did not enforce, it was- a newly introduced treatment and absence of IPTp, manual, as reasons for not using IPTp . There was no statistically significant difference in their reason. Less than half $(47.4 \%$ and $33.6 \%)$ in both public and private providers strongly agreed that IPTp should be taken under observation of health officer. There was no statistically significant difference in their belief.

Table $3 \mathrm{~b}$ showed that more $(71.9 \%)$ of the public providers than (57.15) of the private provider ensured that women take the drugs in the health facility. There was statistically significant difference $(p<0.05)$. Reason for not ensuring that the women take their drug in health facility 
$(17.0 \%)$ of the public providers believe that the patients were aware of the danger of malaria in pregnancy as against $(8.4 \%)$ of private providers who have the same belief, while $(11.7 \%)$ of public providers and (12.6\%) of private providers complained of too many patients (work overload). There was statistically significant difference in their reasons.

Table $3 \mathrm{c}$ showed that the mean number of patient provided with IPTp in both public and private facilities were $113.84 \pm 261.79$ and $59.74 \pm 101.28$ respectively. There was statistically difference $\mathrm{p}=<0.05$.

Majority $(70.2 \%)$ in public and $(69.8 \%)$ in private providers commonly dispensed sulphadoxine/pyrimethamine for IPTp. This is followed by ACT which revealed $(28.1 \%)$ in public and $(30.3 \%)$ in private providers while chloroquine tablets formed (14.0\%) in public and $(15.1 \%)$ in private providers. There was statistically significance difference in their choice of drugs.

\section{DISCUSSION}

This study is a comparative, crosssectional, study which was conducted in Lagos State to compared the chemoprophylaxis of malaria in pregnancy (MIP) by public and private secondary antenatal care (ANC) service providers in Lagos State.

The majority $(84.2 \%)$ of the providers in the public facilities were between the ages of 2029 years while the private facilities had $64.7 \%$ respondents who fell within this age group. The mean ages in the public and private providers were $35.08 \pm 7.5$ and $33.9 \pm 10.8$ years respectively. There was no significant difference in the mean age of the groups. This is not in keeping with a study in Enugu of which the mean age was $28.5 \pm 4.6(16)$. Of the providers in the public facilities $77.8 \%$ were Christians while $96.6 \%$ of providers in the private facilities practiced Christianity. This is keeping with a study in Lagos (15). As expected of a Western state, the majority of the respondents were of the Yoruba tribe with $70.8 \%$ in the public and $36.1 \%$ in the private facility being of the Yoruba tribe. Low percentage of Yorubas in private facility could be that as a Western state, they are to be considered first in state government employment. This is in keeping with the study in Ibadan where majority of the providers were Yorubas (13).

More of the respondents in the public facilities have practiced between 1 to 10years $(69.5 \%)$ while $10.9 \%$ of those in private were within the same year of practice. The mean years of practice in both public and private providers were $9.05 \pm 7.92$ and $9.18 \pm 9.9 \sim$ ) respectively. There was no statistically significant difference in their mean years of practice $(\mathrm{p}=0.902)$. The largest proportion in both cases $(42.7 \%)$ in public and $(26.7 \%)$ in private providers were medical officers. There was a statistically significant difference in the rank of the health providers.

The private providers were more aware of the timing (recommended time to give IPTp) of IPTp and this was not significant. This is in keeping with the study in Enugu where the private providers were more aware of the timing than the public providers (6). The proper timing is very important so as to have full benefits of the policy which should be at least two or three times -during pregnancy (9). Proper timing with 3 or more doses of sulphadoxine-pyrimethamine was associated with higher birth weight and lower risk of low birth weight than the standard 2 dose regimens (12).

A higher proportion of private providers agreed that daily and weekly chemoprophylaxis using daraprin, chloroquine and proguanil was still in use and very beneficial compared to the public. This is in agreement with the study in Enugu which obtained the same result (6). This is not in conformity with literature as the daily and weekly chemoprophylaxis have been replaced with intermittent preventive treatment of malaria in pregnancy (IPTp) using sulphadoxine /pyrimethamine $(1,5)$.

In recommended drug of choice for IPTp majority of the providers in the private and public facilities used sulphadoxine-pyrimethamine while some in both public and private facilities used ACT and some Artesunate/ Artemisinin monotherapy. This is in keeping with a study in Enugu with $90 \%$ in private and $82.1 \%$ in public (6) but in contrast with another study carried out at the 68 Nigeria Army Reference Hospital Yaba, Lagos where only $3.7 \%$ of the cases reviewed received sulphadoxine-pyrimethamine (15).

A little above half in both public and private providers knew the correct interval between doses of IPTp which is one month apart, this is in keeping with a study done in Ibadan in which only half of the respondents were aware of the correct timing (13). The implication of not conforming to current practices in chemoprophylaxis in pregnancy included increased foetal, perinatal and maternal morbidity and mortality from malaria (13).

More $(32.8 \%)$ of the private providers 
agreed that daily and weekly chemoprophylaxis using Daraprin, Chloroquin and Proguanil was still in use and very useful compared to (32.2\%) of the public providers. This is in contrast with the current WHO guideline that adopted IPTp with sulphadoxine-pyrimethamine as the gold standard for prevention of malaria in pregnancy (2). In 1998, it was proposed, then finally implemented in 2004, that weekly or daily chemoprophylaxis should no longer be recommend, but replaced by intermittent preventive treatment for all pregnant women living in areas of stable malaria transmission $(1,2)$. And Nigeria adopted IPTp as a strategy in 2005 to replace weekly prophylaxis (5). More of the public providers considered IPTp very useful as against the private providers and this is in contrast with the study done in Enugu where more of the private providers than the public providers considered IPTp more useful (6).

Less than half of both public and private providers strongly agreed that IPTp should be taken under observation of health officer. However, more of the public providers ensure that the women take the drugs in health facility than the private providers and this was significant $(p=0.012)$. This did not quite agree with the conclusion made in the study conducted in Enugu (6) where they found that the private providers practice direct observation of patient taking the drug in the facility than the public.

However, some of the providers both in private $(42.9 \%)$ and public $(28.1 \%)$ still give IPT -Sulphadoxine-pyrimethamine unsupervised (without direct observation) with the reasons that some women do not eat before coming to ANC, while some insists that the patients are aware of the danger of MIP, some complained of work load, some said this awareness talk given to patient are enough while others complained on laxity in enforcing the regulation as there's no direct supervision arrangement on ground.

The public providers provided IPTp more to the pregnant women compared to private providers. The mean number of patient provided with IPTp in both public and private facilities were $113.84 \pm 261.79$ and $59.74 \pm 101.28$ respectively. This was significant $(\mathrm{p}=0.033)$. This is in keeping with the study done in Enugu (4) where such result was also obtained.

On the choice of drug for IPTp, majority of the public and private provider used sulphadoxine-pyrimethamine as IPTp though some providers both in public and private used ACT, chloroquine, septrin, clindamycin (as adjunct). This is in contrast to a study carried out in Enugu (14) where one tenth of Nigerian obstetricians surveyed do not routinely prescribed IPTp during pregnancy. Also, not in keeping with another study at 68 Army Hospital Lagos where IPT -SP was prescribed for only $3.7 \%$ of cases reviewed, and all received just one dose (15). The fact that some of the providers both in private and public facilities still prescribed ACT, Chloroquine, Antibiotic (septrin), Pyrimethamine,Quinine, as IPTp, shows that the providers may not be fully acquainted with the concept of IPT using sulphadoxine-pyrimethamine (IPT -SP).

Conflict of interest: The authors declare no conflicts of interest.

\section{CONCLUSION}

This study revealed some deficiencies in chemoprophylaxis for malaria in pregnancy in Lagos State, Nigeria. The pattern of chemoprophylaxis prescription among secondary health care providers in Lagos State varied widely among the practitioners which does not fully embraced the evidence based recommendation of the World Health Organization Guideline. The public providers had a better practice and provision of chemoprophylaxis. That only $70.2 \%$ of public providers and $69.8 \%$ of private providers prescribed IPT-Sulphadoxine-Pyrimethamine of malaria revealed again that public providers have better practice of IPTp than private providers.

\section{REFERENCES}

1. Valerie B, Gilles C, Achille M, Michel C. Intermittent preventive treatment for prevention of malaria during pregnancy in high transmission areas. Malaria JBMC 2007; 6:160.

2. WHO: A Strategic Framework for Malaria Prevention and Control during Pregnancy in the African region. Geneva, AFRIMAL J 2004; 04 (01).

3. World Health Organization (WHO). World malaria report. Geneva, 2010 p30-32.

4. Ruth E, Lageuberg CMN: Malaria in pregnancy, a literature review. J Midwifery Women Health 2008; 53(3): 209-15.

5. FMOH: National Guidelines and Strategies for Malaria Prevention and Control during pregnancy. National malaria and vector control division, 2005, Abuja.

6. Ogochukwe CO, Soremekun RO, Ugochukwu B, Shu E, Onwujekwe O. Patterns of case management and chemoprevention for malaria in pregnancy by public and private sector health 
providers in Enugu State, Nigeria BMC Research Notes 2012, ;5:211.

7. Falade CO, Yusuf BO, Fadero FF, Mokuolu OA, Hamer DH. Salsko LA. Intermittent preventive treatment with sulphodoxine - pyrimethamine is effective in preventing maternal and placental malaria in Ibadan, South-Western Nigeria Malar J. 2007; 6:88.

8. Okonofua PE, Prevention of malaria in pregnancy, an important public health challenge. J. Med. Biomed. Res. 2004; 3(1): 5-6.

9. Anders K, Marchart T, Chambo P, Mapunda P, Reyburn H. Timing of intermittent preventive treatment for malaria in pregnancy and the implications of current policy on early uptake in North-east Tanzania. Malar J 2008; 7:79.

10. Chimere OA, Oyibo W A, Agomo P U, Prevalence of malaria in pregnant women in Lagos, South West Nigeria Korean J Parasito1. 2009; 47(2): 179-183.

11. World Health Organization. The African malaria report Geneva 2008 p10-15.

12. Kassoum K, Paul G, Anne ME, in Barani N, Cally $\mathrm{R}$, Abdunoon $\mathrm{M}$, et a1. Intermittent preventive therapy for malaria during pregnancy using 2 vs 3 or more doses of sulphadoxine pyrimethamine and risk of low birth weight in Africa. JAMA, 2013; Feb 13,(3098) 6.

13. Onyeaso NC, Fawole A.O Perception and practice of malaria prophylaxis in pregnancy among health care providers in Ibadan Afr J Rep Health 2007; 11 (2) 60 - 69.

14. Onah EH, Nkuro PO, Nwankwo T. Malaria chemoprophylaxis during pregnancy; a survey of current practice amongst Nigeria obstetrician. Trop J. Ob stet, Gynaecol2006; 23(1): 17-19.

15. Harrison NE, Olufunmilayo TF, Odunukwe NN. Prescription of intermittent preventive therapy (IPTp) among doctors practicing in an army hospital in Lagos, Nigeria Open J of Prev Med 2013;3, (2): 258 - 261

16. Ugwu EO, Iferikigwe ES, Obi S.N. Ugwu AO., Agu PU, Okezie OA. Anti-malaria prescription in pregnancy among general practitioners in Enugu State. South East. Nigeria. Niger Med. J. 2013; 54: 96-9. 
Table 1: Socio-demographic characteristics of Healthcare Providers

\begin{tabular}{|c|c|c|c|c|c|}
\hline \multirow[b]{2}{*}{ Variables } & \multirow{2}{*}{$\begin{array}{l}\text { Public facility (171) } \\
\text { No (\%) }\end{array}$} & \multirow{2}{*}{$\begin{array}{l}\text { Private facility (119) } \\
\text { No (\%) }\end{array}$} & \multirow[t]{2}{*}{$X^{2}$} & \multirow[t]{2}{*}{ Df } & \multirow[t]{2}{*}{ p-value } \\
\hline & & & & & \\
\hline \multicolumn{6}{|l|}{ Age } \\
\hline $15-24$ years & $2 \quad(1.2)$ & $18(0.84)$ & & & \\
\hline $25-34$ years & $98(57.3)$ & $61(51.26)$ & & & \\
\hline $35-44$ years & $46(26.9)$ & $16(13.45)$ & & & \\
\hline $45-54$ years & $23(13.5)$ & $15(12.61)$ & & & \\
\hline 55 years and above & $2(1.2)$ & $9(0.84)$ & & & \\
\hline Mean age & $35.08 \pm 7.57$ & $33.97 \pm 10.82$ & & & 0.308 \\
\hline \multicolumn{6}{|l|}{ Mariral Status } \\
\hline Married & $123(71.9)$ & $72(60.5)$ & 4.159 & 1 & $0.043^{*}$ \\
\hline Single & $48 \quad(28.1)$ & $47(39.5)$ & & & \\
\hline \multicolumn{6}{|l|}{ Religion } \\
\hline Christianity & $133(77.8)$ & $115(96.6)$ & 20.154 & 1 & $0.000^{*}$ \\
\hline Islam & $38 \quad(22.2)$ & $4 \quad(3.4)$ & & & \\
\hline \multicolumn{6}{|l|}{ Ethnic Group } \\
\hline Hausa & $2 \quad(1.2)$ & $1 \quad(0.8)$ & 35.167 & 3 & $0.000^{* * *}$ \\
\hline Igbo & $35 \quad(20.5)$ & $55(46.2)$ & & & \\
\hline Yoruba & $121(70.8)$ & $43(36.1)$ & & & \\
\hline Others & $13(7.6)$ & $20(16.8)$ & & & \\
\hline \multicolumn{6}{|l|}{ Gender } \\
\hline Male & $86(50.3)$ & $28(23.5)$ & 21.067 & 2 & $0.000^{*}$ \\
\hline Female & $85(49.7)$ & $91(76.5)$ & & & \\
\hline \multicolumn{6}{|c|}{ Professional category } \\
\hline Medical doctor & $111(64.9)$ & $47(39.5)$ & 18.279 & 2 & $0.000^{*}$ \\
\hline Nurse & $60 \quad(35.1)$ & $72(60.5)$ & & & \\
\hline
\end{tabular}

****ischer exact p-value, "Statistically significant 
Table 1b: Socio-demographic Characteristics of Healthcare Providers

\begin{tabular}{|c|c|c|c|c|c|}
\hline \multirow[t]{2}{*}{ Variables } & Public facility (171) & Private facility (119) & \multirow[t]{2}{*}{$\mathrm{X}^{2}$} & \multirow[t]{2}{*}{ df } & \multirow[t]{2}{*}{ p-value } \\
\hline & No $\%$ & No $\%$ & & & \\
\hline \multicolumn{6}{|l|}{ Years of Practice } \\
\hline Less than 1 year & $5 \quad(2.9)$ & $64(53.8)$ & & & \\
\hline $1-5$ years & $63(36.8)$ & $8 \quad(6.7)$ & & & \\
\hline $6-10$ years & $56 \quad(32.7)$ & $5 \quad(4.2)$ & & & \\
\hline $11-15$ years & $18(10.5)$ & $23(19.3)$ & & & \\
\hline $16-20$ years & $9 \quad(5.3)$ & $18(15.1)$ & & & \\
\hline More than 20 years & $20(11.7)$ & $1 \quad(0.8)$ & & & \\
\hline Mean & $9.05 \neq 7.92$ & $9.18=9.99$ & & & 0.902 \\
\hline \multicolumn{6}{|l|}{ Current Rank } \\
\hline Consultant & $(1.8)$ & $(5.0)$ & $(43.72)$ & 8 & $0.000^{* * *}$ \\
\hline Registrar & $8 \quad(4.7)$ & $3 \quad(2.5)$ & & & \\
\hline Medical Officer & $73(42.7)$ & $32(26.9)$ & & & \\
\hline House Officer & $26(15.2)$ & $8 \quad(6.7)$ & & & \\
\hline Chief Nursing Officer & $14(8.2)$ & $(4.2)$ & & & \\
\hline Asst Chief Nursing & $3 \quad(1.8)$ & (3.4) & & & \\
\hline \multicolumn{6}{|l|}{ Officer } \\
\hline $\mathrm{PNO}$ & $12(7.0)$ & $(3.4)$ & & & \\
\hline Sister & $24(14.0)$ & $25(21.0)$ & & & \\
\hline Staff & $8 \quad(4.7)$ & $32(26.9)$ & & & \\
\hline
\end{tabular}

Table 2: Provision of Chemoprevention of Malaria in Pregnancy Without IPTp

\begin{tabular}{|c|c|c|c|c|c|}
\hline $\begin{array}{llr}\text { Provision } & & \text { of } \\
\text { Chemoprevention } & \text { of } & \text { MIP } \\
\text { without IPTp } & & \\
\end{array}$ & Public 171 (\%) & Private $119(\%)$ & $\mathbf{X}^{2}$ & df & p-value \\
\hline \multicolumn{6}{|l|}{$\begin{array}{l}\text { Use of daraprin, chloroquine } \\
\text { and paludrine }\end{array}$} \\
\hline Yes & $54(31.6)$ & $37(31.1)$ & 0.008 & 1 & 0.930 \\
\hline No & $117(68.4)$ & $82(68.9)$ & & & \\
\hline \multicolumn{6}{|l|}{ Reason for use } \\
\hline It is effective & $39(22.8)$ & $29(24.4)$ & 2.654 & 3 & 0.427 \\
\hline $\begin{array}{l}\text { Reduces complications in } \\
\text { pregnancy }\end{array}$ & $10(5.8)$ & $6(5.0)$ & & & \\
\hline $\begin{array}{l}\text { Approved by the Government } \\
\text { and WHO }\end{array}$ & $5(2.9)$ & $2(1.7)$ & & & \\
\hline Not applicable & $171(68.4)$ & $82(68.9)$ & & & \\
\hline \multicolumn{6}{|l|}{$\begin{array}{l}\text { No of women } \\
\text { chemoprophylaxis }\end{array}$} \\
\hline $0-50$ & $124(72.5)$ & $98(82.4)$ & & & \\
\hline $51-100$ & $29(17.0)$ & $18(15.1)$ & & & \\
\hline Above 100 & $18(10.5)$ & $3(2.5)$ & & & \\
\hline Mean & $5903 \neq 75.60$ & $40.88 \neq 40.43$ & & & $0.017^{*}$ \\
\hline
\end{tabular}


Table 2b: Provision of Chemoprevention of Malaria in Pregnancy Without IPTp

\begin{tabular}{|c|c|c|c|c|c|}
\hline $\begin{array}{l}\text { Provision of Chemoprevention of } \\
\text { MIP without IPTp }\end{array}$ & $\begin{array}{l}\text { Public } \\
(\%)\end{array}$ & $\begin{array}{l}\text { Private } 119 \\
(\%)\end{array}$ & $\mathrm{X}^{2}$ & df & p-value \\
\hline \multicolumn{6}{|l|}{$\begin{array}{l}\text { Drugs given for chemoprophylaxis } \\
\text { of malaria in pregnancy }\end{array}$} \\
\hline $\begin{array}{l}\text { Artemisinin-based combination } \\
\text { therapy }\end{array}$ & $49(28.7)$ & $35(29.4)$ & 11.917 & 5 & 0.036 \\
\hline Sulphadoxine/pyrimethamine & $118(69.0)$ & $89(74.8)$ & & & \\
\hline Chloroquine & $33(19.3)$ & $21(17.6)$ & & & \\
\hline Quinine & $22(12.9)$ & $2(1.7)$ & & & \\
\hline Artemisin/artesunate & $20(11.7)$ & $12(10.1)$ & & & \\
\hline Others: daraprim, septrin & $4(2.3)$ & $5(4.2)$ & & & \\
\hline
\end{tabular}

$* *$ multiple response

Table 3: Provision of Chemoprevention for Malaria in pregnancy with IPTp

\begin{tabular}{|c|c|c|c|c|c|}
\hline $\begin{array}{l}\text { Provision of Chemoprevention of } \\
\text { MIP with IPTp }\end{array}$ & $\begin{array}{l}\text { Public } 171 \\
\text { (\%) }\end{array}$ & $\begin{array}{l}\text { Private } \\
(\%)\end{array}$ & $\mathrm{X}^{2}$ & df & p-value \\
\hline \multicolumn{6}{|l|}{$\begin{array}{l}\text { Whether IPTp is used as preventive } \\
\text { strategy }\end{array}$} \\
\hline Yes & $106(93.6)$ & $118(99.2)$ & 0.015 & 1 & $0.999^{* * *}$ \\
\hline No & $11(6.4)$ & $1(0.8)$ & & & \\
\hline \multicolumn{6}{|l|}{ Reason for not using IPTp } \\
\hline $\begin{array}{l}\text { The laboratory tells if patients have } \\
\text { malaria }\end{array}$ & $2(1.2)$ & $0(0.0)$ & 9.244 & 7 & 0.247 \\
\hline Hospital do not enforce it & $3(1.8)$ & $0(0.0)$ & & & \\
\hline It is a newly introduced treatment & $1(0.6)$ & $0(0.0)$ & & & \\
\hline Absence if IPTp manual & $1(0.6)$ & $0(0.0)$ & & & \\
\hline Treats patients symptomatically & $2(1.2)$ & $0(0.0)$ & & & \\
\hline Unavailable & $2(1.2)$ & $0(0.0)$ & & & \\
\hline Unknown & $0(0.0)$ & $1(0.8)$ & & & \\
\hline Not applicable & $162(94.8)$ & $118(99.2)$ & & & \\
\hline \multicolumn{6}{|l|}{ Best time to give IPTp } \\
\hline First trimester & $29(17.0)$ & $31(26.1)$ & 6.869 & 4 & 0.125 \\
\hline Second trimester & $108(63.2)$ & $71(59.7)$ & & & \\
\hline Third trimester & $5(2.9)$ & $5(4.2)$ & & & \\
\hline After quickening & $0(0.0)$ & $1(0.8)$ & & & \\
\hline Not applicable & $26(15.2)$ & $9(7.6)$ & & & \\
\hline \multicolumn{6}{|l|}{$\begin{array}{l}\text { IPTp should be under observation } \\
\text { of health officer }\end{array}$} \\
\hline Strongly agree & $81(47.4)$ & $40(33.6)$ & 7.336 & 4 & 0.119 \\
\hline Agree & $36(21.1)$ & $39(32.8)$ & & & \\
\hline Disagree & $18(10.5)$ & $15(12.6)$ & & & \\
\hline Indifferent & $32(18.7)$ & $23(19.3)$ & & & \\
\hline Strongly disagree & $4(2.3)$ & $2(1.7)$ & & & \\
\hline
\end{tabular}


Table 3b: Provision of Chemoprevention for Malaria in pregnancy with IPTp

\begin{tabular}{|c|c|c|c|c|c|c|}
\hline $\begin{array}{l}\text { Provision of Chemoprevention of } \\
\text { MIP with IPTp }\end{array}$ & $\begin{array}{l}\text { Public } 171 \\
(\%)\end{array}$ & $\begin{array}{l}\text { Private } \\
(\%)\end{array}$ & 119 & $\mathbf{X}^{2}$ & df & p-value \\
\hline \multicolumn{7}{|l|}{ Provision of direct observed IPTp } \\
\hline Yes & $123(71.9)$ & $68(57,1)$ & & 6.824 & 1 & $0.012^{*}$ \\
\hline No & $48(28.1)$ & $51(42.9)$ & & & & \\
\hline \multicolumn{7}{|l|}{ Reasons for saying "no" } \\
\hline $\begin{array}{l}\text { Some don't eat before coming for } \\
\text { ANC }\end{array}$ & $3(1.8)$ & $7(5.9)$ & & 11.822 & 9 & 0.224 \\
\hline $\begin{array}{l}\text { The patients are aware of the danger } \\
\text { of malaria in pregnancy }\end{array}$ & $12(17.0)$ & $10(8.4)$ & & & & \\
\hline Too many patients & $20(11.7)$ & 15 (12.6) & & & & \\
\hline Indifferent & $0(0.00)$ & $2(1.7)$ & & & & \\
\hline They can take the drugs at home & $3(1.8)$ & $3(2.5)$ & & & & \\
\hline $\begin{array}{l}\text { The patients are mature enough to } \\
\text { comply }\end{array}$ & $1(0.6)$ & $4(3.4)$ & & & & \\
\hline Pharmacists dispense the drugs & $1(0.6)$ & $1(0.8)$ & & & & \\
\hline Patients are given awareness talk & $3(1.8)$ & $8(6.7)$ & & & & \\
\hline $\begin{array}{l}\text { It may not be convenient for the } \\
\text { woman }\end{array}$ & $2(1.2)$ & $1(0.8)$ & & & & \\
\hline $\begin{array}{l}\text { There's no direct supervision } \\
\text { arrangement made }\end{array}$ & $3(1.8)$ & $0(0.00)$ & & & & \\
\hline Not applicable & $123971.9)$ & $68(57.1)$ & & & & \\
\hline
\end{tabular}

*Statistically significant

Table 3c: Provision of Chemoprevention for Malaria in pregnancy with IPTp

\begin{tabular}{|c|c|c|c|c|c|}
\hline $\begin{array}{l}\text { Provision of Chemoprevention of } \\
\text { MIP with IPTp }\end{array}$ & Public $171(\%)$ & Private $119(\%)$ & $\mathbf{X}^{2}$ & df & $\begin{array}{l}\text { p- } \\
\text { value }\end{array}$ \\
\hline \multicolumn{6}{|l|}{$\begin{array}{l}\text { No of patient provided with IPTp in } \\
\text { one month }\end{array}$} \\
\hline$<50$ & $80(46.8)$ & $67(56.3)$ & & & \\
\hline $50-100$ & $63(36.8)$ & $37(31.1)$ & & & \\
\hline$>100$ & $28(16.4)$ & $15(12.6)$ & & & \\
\hline Mean & $113.84 \pm 261.79$ & $58.74+101.28$ & & & $\begin{array}{l}0.033 \\
*\end{array}$ \\
\hline \multicolumn{6}{|l|}{ Drug of choice of IPTp } \\
\hline Artemisin-based combination therapy & $48(28.1)$ & $36(30.3)$ & 14.048 & 8 & 0.081 \\
\hline Sulphadoxine/pyrimethamine & $120(70.2)$ & $83(69.8)$ & & & \\
\hline Chloroquine injection & $16(9.4)$ & $7(5.9)$ & & & \\
\hline Chloroquine tablets & $24(14.0)$ & $18(15.1)$ & & & \\
\hline Antibiotics: septrin,clindamycin & $8(4.7)$ & $11(9.2)$ & & & \\
\hline Quinine & $18(10.5)$ & $4(3.4)$ & & & \\
\hline Artemisin/artesunatemonotherapy & $12(7.0)$ & $7(5.9)$ & & & \\
\hline Proguanil & $19(11.1)$ & $20(16.8)$ & & & \\
\hline Pyrimethamine & $11(6.4)$ & $17(14.3)$ & & & \\
\hline Others: none & $0(0.0)$ & & & & \\
\hline
\end{tabular}

